\title{
In vitro Antioxidant Activities of Natural Polysaccharides: An overview
}

\author{
Boris V. Nemzer ${ }^{1,2}$, Diganta Kalita ${ }^{1}$, Alexander Ya Yashin ${ }^{3}$, Nikolay E. Nifantiev ${ }^{4} \&$ Yakov I. Yashin ${ }^{3}$ \\ ${ }^{1}$ Department of Research \& Development, VDF FutureCeuticals, Inc., Momence, IL 60954, USA \\ ${ }^{2}$ Department of Food Science and Human Nutrition, University of Illinois at Urbana-Champaign, Urbana, IL \\ 61801, USA \\ ${ }^{3}$ International Analytical Center of Zelinsky Institute of Organic Chemistry, Moscow 119991, Russia \\ ${ }^{4}$ Laboratory of Glycoconjugate Chemistry of Zelinsky Institute of Organic Chemistry, Moscow 119991, Russia \\ Correspondence: Boris V. Nemzer, Department of Research \& Development, VDF FutureCeuticals, Inc., \\ Momence, IL 60954, USA. Tel: 1-815-507-1427. E-mail: bnemzer@ futureceuticals.com
}

Received: August 30, $2019 \quad$ Accepted: September 24, $2019 \quad$ Online Published: October 29, 2019

doi:10.5539/jfr.v8n6p78

URL: https://doi.org/10.5539/jfr.v8n6p78

\begin{abstract}
Polysaccharides are naturally occurring biomacromolecules composed of carbohydrate molecules linked by glycosidic bonds. A number of polysaccharides are known to possess beneficial therapeutic effects against inflammation, diabetes, cardiovascular diseases, and cancers. Indeed, polysaccharides are reportedly effective free radical scavengers and antioxidants, thereby playing a critical role in the prevention of damage to living organisms under oxidative stress. In this review we provide an overview of the sources, extraction, and antioxidant activities of some natural polysaccharides.
\end{abstract}

Keywords: polysaccharide, antioxidant activity, health benefits

\section{Introduction}

Polysaccharides are naturally occurring biomacromolecules composed of carbohydrate molecules linked by glycosidic bonds. These molecules play an important role in the development of pharmaceuticals, food, nutritional products, and biodegradable packaging materials (Yu, Shen, Song, \& Xie, 2018; Copeland, Blazek, Salman, \& Tang, 2009; Yang \& Zhang, 2009; Cazon, Velazquez, Ramirez, \& Vazquez, 2017). They are commonly derived from plants, fruits, vegetables, herbs, algae, mushrooms, and microorganisms (Kardasova \& Machova, 2006; Zhang et al., 2019; Maity, Maity, \& Dasgupta, 2019; Han et al., 2019; Hajji et al., 2019, Liu, Ooi, \& Chang, 1997; Huang, Siu, Wang, Cheeung, \& Wu, 2013; Hu, Gen, Zhang, \& Jiang, 2001; Guo et al., 2010; Kodali \& Sen, 2008).

Polysaccharides can be either linear or branched and they can be classified as homopolymers if the polymer composed of identical monosaccharides, or heteropolymers, if the polysaccharide is composed of two or more different monosaccharides. The structural composition of polysaccharides is rather complex since the monosaccharide units linked through glycosidic linkages can be composed of different sequences, degrees of polymerization, and branching. As such, the structures of these compounds are determined using various sophisticated analytical and spectroscopic techniques, such as fourier transform infrared spectroscopy (FT-IR), ultraviolet spectrophotometry (UV-Vis), nuclear magnetic resonance (NMR) spectrophotometry, gas chromatography-mass spectrophotometry (GC-MS), and liquid chromatography-mass spectrophotometry (LC-MS). It has also been found that their structural properties vary based on the natural sources, processing methods, extraction methods, and variety of agricultural or botanical species (Wang, Hu, Nie, Yu, \& Xie, 2016; Wang et al., 2013; Cui, 2005).

One of the major applications of polysaccharides is their uses as a staple food source for humans. For example, starch is key ingredient in various foods supplying 50-70\% of the energy in a human diet. Upon digestion, starch can be hydrolyzed to glucose, which is an integral part of the development of brain and red blood cells. The rate of digestibility of polysaccharides has an active role in determining the glycemic index (GI), i.e., the level of glucose in the blood. More specifically, a rapid rate of digestibility results in a higher GI and can leads to complications such as type II diabetes and obesity. However, polysaccharides that exhibit beneficial health 
properties are of great interest in the food industry as a number of these compounds have been shown to exhibit anti-inflammatory, antidiabetics, and anticancer properties, in addition to preventing cardiovascular diseases (Yu, et al., 2018; Copeland et al., 2009; Yang \& Zhang, 2009; Cazon et al., 2017; Kardasova \& Machova, 2006). Polysaccharides are also used in many biomedical and biological applications, such as tissue engineering, drug delivery, wound healing, and biosensors (Yu, Shen, Song, \& Xie, 2018; Copeland, Blazek, Salman, \& Tang, 2009; Kardasova \& Machova, 2006; Zhanget al., 2019). More importantly, some have been employed as antioxidants both in vitro and in vivo due to their free radical scavenging properties that play a critical role in the prevention of damage from oxidative stress. Thus, in this review, we provide an overview of the sources, extraction, in vitro antioxidant properties of some natural polysaccharides.

\section{Sources of Polysaccharide}

\subsection{Plant Polysaccharides}

Among the various natural polysaccharides, the major polysaccharides tend to be extracted from plant materials. Several polysaccharides isolated from plant sources have been reported to exhibit significant antioxidant activities both in vivo and in vitro. For example, two polysaccharides isolated from Rosa rugosa petals (RRPS, namely RRPS-1 and RRPS-2) were analyzed for their antioxidant activities and it was found that RRPS-2 had a good radical scavenging potential (Zhang et al., 2019). In addition, a water soluble arabinoxylan (APPS), with a molecular weight of $\sim 1.49 \times 10^{5}$ Da was isolated from the green stem of Andrographis paniculate and showed strong antioxidant activity against superoxide and hydroxyl free radicals (Maity, Maity, \& Dasgupta, 2019). Kiwifruit polysaccharides also exhibited high antioxidant activities (Han et al., 2019). Furthermore, Hajji et al., (2019) isolated a novel water-soluble polysaccharide (PLP1) from the root barks of Periploca laevigata by hot water extraction and further purification by diethylaminoethyl cellulose (DEAE)-sepharose chromatography, and this compound exhibited a strong antioxidant activity. Recently, Wei et al., (2019) isolated polysaccharides from seabuckthorn berries (PSB) and investigated the role of microwave power on their antioxidant activities. Furthermore, a water-soluble polysaccharide (MWP) with a galactose-, glucose-, mannose-, fructose with 1:33.2:8.4:7.2 was successfully isolated from Malus micromalus Makino fruit (Hui, Jun, \& Chuang, 2019) and this polysaccharide showed degrees of scavenging effects on hydroxyl, DPPH (2,2-ddiphenyl-2-picrylhydrazyl), and superoxide radicals in a dose dependent manner. Zhu et al., (2009) isolated two major polysaccharide fractions composed of arabinose, galactose, and glucose, which were associated with protein portions from Huaza No. 4 rapeseed meal using column chromatography and ethanol precipitation, and this compound also exhibited a significant antioxidant activity ( $\mathrm{Zhu}$ and $\mathrm{Wu}, 2009$ ). In addition, three polysaccharides with molecular weights of 218, 178, and $60 \mathrm{kD}$ were extracted from the roots of Arctium lappa L. (ALPs) and were reported to exhibit strong scavenging activities for DPPH, hydroxyl, and superoxide radicals both in vitro and in vivo (Jiang et al., 2019). Furthermore, Litchi pulp polysaccharide extracted from Litchi Chinensis Sonn. showed a dose dependent antioxidant activity against DPPH, hydroxyl, and superoxide radicals, (Kong et al., 2010) while Ginkgo biloba leaves (GBLs), a common herbal remedy, exhibited noticeable scavenging effects on superoxide radicals and ABTS (2, 2-azino-bis (3-ethylbenzothiazoline-6-sulphonic acid) radicals (Ren et al., 2019).

\subsection{Fungal Polysaccharide}

Fungal cell walls are composed of polysaccharides such as glucans, chitin, and mannans, which contain glucose, $\mathrm{N}$-acetylglucosamine, and mannose repeating units, respectively. However, the structures of these species also differ; for example glucans are composed of glycosidic linkages including branched glucans and linear glucans, while chitin is a water insoluble polymer composed of $\beta 1,4$-linked $\mathrm{N}$-acetylglucosamine units. Studies into the beneficial effects of these polysaccharides indicated that mushrooms polysaccharides tend to exhibit significant antioxidant properties. For example, Inonotus oblique mushrooms produce a crude extract polysaccharide, which is widely used in Russian folk medicine and is reported to have significant medicinal and antioxidant properties (Mu et al., 2012). In addition, a polysaccharide from Hericium erinaceus mushrooms exhibits a strong in vitro antioxidant activity in addition to neuroprotective effects on $\beta$-induced neurotoxicity in neurons (Cheng, Tsai, Lien, Lee, \& Sheu, 2016). Furthermore, polysaccharides extracted from the edible mushroom Tricholoma mongolicum exhibited in vitro antioxidant activities in a dose-dependent manner (Zhao et al.,2016) while fucogalactomannan obtained from the Tylopilus ballouii mushroom inhibited superoxide and hydroxyl radicals with $\mathrm{IC}_{50}$ values of 1.25 and $1.6 \mathrm{mg} / \mathrm{mL}$, respectively (Lima et al., 2016). Moreover, a water-soluble $\beta$-glucan isolated from the hot water extract of the edible mushroom Entoloma lividoalbum (Kühner \& Romagn) Kubička stimulated the production of macrophages, splenocytes, and thymocytes, in addition to exhibiting hydroxyl and superoxide radical scavenging activities and reducing properties (Maity, et al., 2015). Indeed, it has been reported that antioxidant activities of these fungi originated from their component polysaccharides and 
polysaccharide -protein complexes (Tseng, Yang, \& Mau, 2008; Wu \& Wang, 2009; Alzorqi, Sudheer, Lu, Manickam, 2016; Chen, Zhong, Zeng, \& Ge, 2008). In this context, Chen et al., (2008) reported that the administration of polysaccharides lentinans from Lentinus edodes could decrease the oxidative stress induced by a high-fat diet in rats (Chen, Zhong, Zeng, \& Ge, 2008).

\subsection{Bacterial Polysaccharide}

Bacterial polysaccharides are biomacromolecules that are anchored to the cell surface by lipid and exist as extracellular polysaccharides, peptidoglycans, lipopolysaccharides, capsules and exopolysaccharides. Bacterial stains such as Staphylococcus epidermidis, Staphylococcus aureus, Escherichia coli, Bordetella bronchiseptica, Actinobacillus pleuropneumoniae, and Yersinia pestis contains high level of polysaccharides in the form of extracellular polysaccharides (EPS). More specifically, Guo et al., (2010) reported that two polysaccharide isolated from the marine bacterium Edwardsiella tarda exhibited a good antioxidant activity against hydroxyl and DPPH radicals, while Kodali et al., (2008) isolated an EPS from the probiotic bacterium Bacillus coagulans and confirmed that it exhibited a significant antioxidant activity (Guo et al., (2010); Kodali \& Sen, 2008). Moreover, Raza et al., (2011) reported that an EPS from Paenibacillus polymyxa possessed a good superoxide scavenging activity in addition to a moderate inhibition of lipid peroxidation (Raza, Makeen, Wang, Xu, \& Qirong, 2011).

\subsection{Animal Polysaccharide}

Animal polysaccharides as glycogens composed of $\alpha-1,4$-glycosidic bonds with branched $\alpha-1,6$ bonds present at approximately every tenth monomer. These polysaccharides are used to store energy and are produced by the liver and the muscles during glycogenesis. Some examples of polysaccharides found in the human body are hyaluronic acid, chondoitrin sulfate, dermatan sulfate, keratan sulfate and heparin. A study into the antioxidant activity of a polysaccharide from Hyriopsis cumingii (HCp) showed both in vitro and in vivo free radical scavenging, in addition to an increase in the activities of antioxidant enzymes in a dose-dependent manner (Qiao et al., 2009). A free neutral polysaccharide was extracted from the mucus of the loach (Misgurnus anguillicaudatus) and their effects on the removal of reactive oxygen species were examined. Indeed, the efficiently removal of $\bullet \mathrm{O} 2, \cdot \mathrm{OH}, \mathrm{H}_{2} \mathrm{O}_{2}$ and other active oxygen compounds were confirmed and these polysaccharides were found to significantly protect DNA chains from damage by free radicals (Zhang, Wang, \& Dong, 2011). Chitin is one of the main components of cell walls in fungi, radulas of mollusks and is a linear homopolysaccharide comprising N-acetyl-glucosamine. Ngo et al., (2008) employed acidic hydrolysis for the isolation of a polysaccharide from crab chitin and upon investigation of its cellular antioxidant effects, they observed free radical scavenging effects (Ngo, Kim, \& Kim, 2008).

\subsection{Algal Polysaccharide}

Fucoidan is a natural sulfated polysaccharide that contains fucose and is known to exhibit numerous beneficial health properties due to the presence of the sulphate ester group. Algal polysaccharides are generally found in the form of alginates, fucans, laminarans, cellulose, and sulfated galactans. More specifically, Zhang et al., (2010) found that fucoidan had promising antioxidant activity toward superoxide radicals rather than hydroxyl and DPPH radicals and brown algae containing sulfated polysaccharides showed significant antioxidant properties (Zhang et al., 2010). In addition, Sokolvoa et al., (2011) reported that sulfated polysaccharides, namely carrageenans, isolated from red algae possessed strong antioxidant activities both in vivo and in vitro due to stimulation of the catalytic activity of superoxide dismutase (SOD) (Sokolova et al., 2011). Both the molecular mass and sulfate content in fucoidan play a significant role in determining its radical scavenging activity and, a positive correlation with the sulfate content has been demonstrated. It was also reported that the sulfated and acetylated derivatives of polysaccharides extracted from the red algae Gracilariopsis lemaneiformis exhibited strong antioxidant activities, although certain derivatives exhibited stronger activities than the unmodified compounds (Wang et al., 2019).

\section{Polysaccharide Extraction, Isolation and Characterization}

Water is commonly employed as a solvent for the extraction of polysaccharides. However hot water was found to be better extracting solvents than the cold water. Several polysaccharides were extracted from various sources as listed in the table 1 by using water with temperatures $50-100{ }^{\circ} \mathrm{C}$. Higher temperature improved the extraction of polysaccharide. In most of the cases the polysaccharides have been isolated using chromatography such as anion chromatography, DEAE column chromatography and gel filtration after ethanol precipitation, and deproteination. Figure 1 represents a general strategic extraction and purification of polysaccharide form various polysaccharide sources. Pure Garlic polysaccharide was extracted by using hot water. These polysaccharides were isolated and separated by column chromatography on Sephadex G200 and washed with distilled water and then 
characterised by ${ }^{13} \mathrm{C}$ and ${ }^{31} \mathrm{P}$ NMR spectroscopy (Chen \& Huang, 2019). Pure pumpkin polysaccharides were extracted by hot water after purification by ethanol precipitation and dialysis. Further sulfated and phosphorylated pumpkin polysaccharides were characterized by IR and ${ }^{13} \mathrm{C}$ NMR spectroscopy (Chen \& Huang, 2019). Cushaw polysaccharide have been extracted with water at $100{ }^{\circ} \mathrm{C}$ after ethanol precipitation followed by dialysis and sulfated and phosphorylated polysaccharide have been prepared with different degrees of substitution. Substituted polysaccharides have been characterized by IR and NMR spectroscopy (Chen \& Huang, 2018). Chen et al., (2019) extracted and isolated polysaccharide with potential antioxidant activity from native ginseng by hot water and characterized by IR and NMR spectroscopy (Chen \& Hunag, 2019).

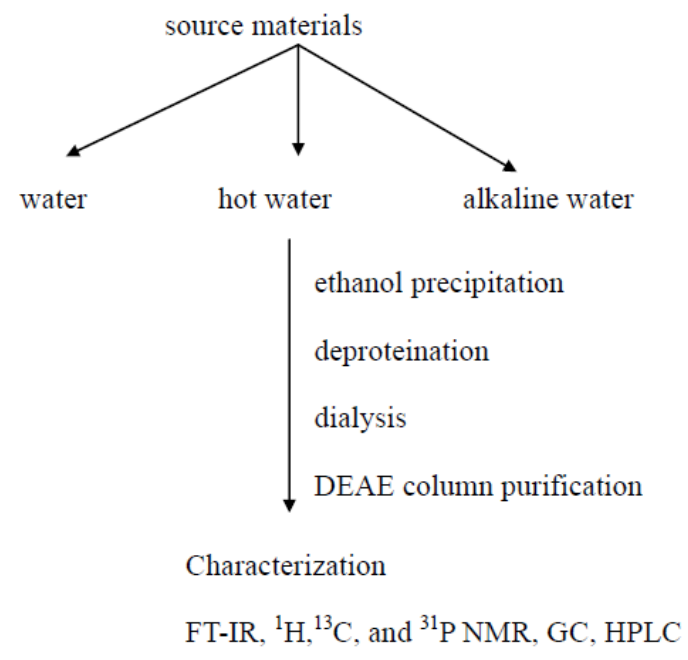

Figure 1. Schematic representation of extraction and characterization of polysaccharides

It has been observed that some advanced treatments such microwave irradiation, sonication, and other irradiation treatments have also been adopted to optimize polysaccharide extraction (Table 1). Furthermore, the extracted crude polysaccharides have been successfully purified by column chromatography. 
Table 1. Sources, extraction methods, purifications, characterizations for some polysaccharides

\begin{tabular}{|c|c|c|c|c|}
\hline sources & solvent & treatment and/or processing & characterisation & ref \\
\hline $\begin{array}{l}\text { Polygonatum } \\
\text { sibiricum }\end{array}$ & water & $\begin{array}{l}\text { microwave, ethanol precipitation, } \\
\text { diethylaminoethyl cellulose-52 } \\
\text { anion-exchange chromatography }\end{array}$ & $\begin{array}{l}\text { high performance gel } \\
\text { chromatography (HPGC) }\end{array}$ & $\begin{array}{l}\text { Zhang et } \\
\text { al., (2019) }\end{array}$ \\
\hline $\begin{array}{l}\text { Fritillaria } \\
\text { pallidiflora }\end{array}$ & water & $\begin{array}{l}\text { anion-exchange and gel-permeation } \\
\text { chromatography }\end{array}$ & FT-IR, NMR, SEM & $\begin{array}{l}\text { Rozi et } \\
\text { al., (2019) }\end{array}$ \\
\hline kiwifruit & water & microwave, ultrasound & $\begin{array}{l}\text { FT-IR, high performance size } \\
\text { exclusion chromatography } \\
\text { (HPSEC), HPLC }\end{array}$ & $\begin{array}{l}\text { Han et al., } \\
\text { (2019) }\end{array}$ \\
\hline Periploca laevigata & water & DEAE-sepharose chromatography & $\begin{array}{l}\text { UHPLC, GC-MS, FT-IR, }{ }^{1} \mathrm{H} \\
\text { NMR and }{ }^{13} \mathrm{C} \text { NMR }\end{array}$ & $\begin{array}{l}\text { Haaji et } \\
\text { al., (2019) }\end{array}$ \\
\hline $\begin{array}{l}\text { Ginkgo biloba } \\
\text { leaves }\end{array}$ & water & $\begin{array}{l}\text { DEAE (diethylaminoethanol) Sepharose Fast } \\
\text { Flow column }\end{array}$ & $\begin{array}{l}\text { high performance liquid } \\
\text { chromatography (HPLC), IR }\end{array}$ & $\begin{array}{l}\text { Ren et al., } \\
\text { (2019) }\end{array}$ \\
\hline Inonotus obliquus & water & $\begin{array}{l}\text { anion-exchange DEAE cellulose column and } \\
\text { Sephadex G-200 gel }\end{array}$ & $\begin{array}{l}\text { IR, Liquid Chromatography, } \\
\text { HPGPC, }\end{array}$ & $\begin{array}{l}\text { Hu et al., } \\
\text { (2016) }\end{array}$ \\
\hline Mung beans & alkaline water & $\begin{array}{l}\text { purified and separated by anion exchange and } \\
\text { gel filtration }\end{array}$ & HPSEC, GC & $\begin{array}{l}\text { Yao et al., } \\
(2016)\end{array}$ \\
\hline Anji Baicha & hot water & - & - & $\begin{array}{l}\text { Zhang et } \\
\text { al., (2016) }\end{array}$ \\
\hline $\begin{array}{l}\text { Paecilomyces } \\
\text { hepiali HN1 }\end{array}$ & hot water & - & HPLC & $\begin{array}{l}\text { Wu et al., } \\
\text { (2016) }\end{array}$ \\
\hline Poria cocos & hot water & ultrasonic, microwave, enzyme assisted & IR & $\begin{array}{l}\text { Wang et } \\
\text { al., (2016) }\end{array}$ \\
\hline $\begin{array}{l}\text { Artemisia } \\
\text { sphaerocephala }\end{array}$ & water & $\begin{array}{l}\text { ultrasound assisted, sulfated with } \\
\text { triphenylchloromethane }\end{array}$ & HPLC, IR & $\begin{array}{l}\text { Zheng et } \\
\text { al., (2016) }\end{array}$ \\
\hline Tangerines peel & water & $\begin{array}{l}\text { microwave assisted, purified by anion } \\
\text { exchange and gel filtration }\end{array}$ & IR & $\begin{array}{l}\text { Chen et } \\
\text { al., (2016) }\end{array}$ \\
\hline Blackcurrant fruit & water & pressurised water extraction & GC, HPLC, and IR & $\begin{array}{l}\text { Xu et al., } \\
(2016)\end{array}$ \\
\hline $\begin{array}{l}\text { Dipsacus } \\
\text { asperoides }\end{array}$ & water & ultrasonic power & & $\begin{array}{l}\text { Tan et al., } \\
\text { (2015) }\end{array}$ \\
\hline $\begin{array}{l}\text { Chrysanthemum } \\
\text { morifolium }\end{array}$ & hot water & $\begin{array}{l}\text { anion exchange, DEAE -cellulose column, } \\
\text { gel filtration }\end{array}$ & partial acid hydrolysis and NMR & $\begin{array}{l}\text { Zheng et } \\
\text { al., (2015) }\end{array}$ \\
\hline Rana chensinesis & water & & HPLC, GC, IR & $\begin{array}{l}\text { Wang et } \\
\text { al., (2015) }\end{array}$ \\
\hline $\begin{array}{l}\text { Stachys sieboldii } \\
\text { Miq }\end{array}$ & water & DEAE Sepharose, Sepharose CL-6B & HPLC, GC & $\begin{array}{l}\text { Feng et } \\
\text { al., (2015) }\end{array}$ \\
\hline $\begin{array}{l}\text { Fortunella } \\
\text { margarita }\end{array}$ & water & $\begin{array}{l}\text { ultrasonic power, purified DEAE Sepharose, } \\
\text { Sepharose CL-6B }\end{array}$ & UV-Vis, HPLC, NMR & $\begin{array}{l}\text { Zeng et } \\
\text { al., (2015) }\end{array}$ \\
\hline Rana chensinesis & water & DEAE Sepharose, Sepharose CL-6B & - & $\begin{array}{l}\text { Wang et } \\
\text { al., (2015) }\end{array}$ \\
\hline $\begin{array}{l}\text { Radix Cyathulae } \\
\text { officinalis }\end{array}$ & water & Water soluble & IR, GCMS, GPC & $\begin{array}{l}\text { Han et al., } \\
(2015)\end{array}$ \\
\hline Cucurbita moschata & water & ultrasound and enzyme & - & $\begin{array}{l}\text { Wu et al., } \\
(2014)\end{array}$ \\
\hline Isochrysis galbana & water & anion exchange chromatography and gel & IR, ESI-MS, NMR & $\begin{array}{l}\text { Sun et al., } \\
(2014)\end{array}$ \\
\hline Tremella fuciformis & water & $\mathrm{Fe}^{2+} / \mathrm{Vc} / \mathrm{H}_{2} \mathrm{O}_{2}$ & UV-Vis, IR, HP-GC & $\begin{array}{l}\text { Zhang et } \\
\text { al., (2014) }\end{array}$ \\
\hline garlic & $\begin{array}{l}\text { petroleum ether, } \\
\text { acetone, } \\
\text { methanol }\end{array}$ & cellulase assisted & - & $\begin{array}{l}\text { Pan et al., } \\
(2014)\end{array}$ \\
\hline Ficus microcarpa & water & ultrasound & IR spectroscopy & $\begin{array}{l}\text { Jiang et } \\
\text { al., (2014) }\end{array}$ \\
\hline
\end{tabular}




\section{Mechanisms of Antioxidant Properties of the Polysaccharide}

\subsection{Antioxidant Activities by Crude Polysaccharide Extract and Polysaccharide Conjugates}

Numerous literatures exist regarding the health benefits of polysaccharides, where most of the studies were carried out using crude polysaccharide extracts. Interestingly, the presence of proteins, amino acid, peptides, organic acid, and other components appeared to enhance the antioxidant properties since, the purified polysaccharides tended to exhibit significantly lower antioxidant activities than the crude polysaccharides. For example, Ennaifer et al., (2018) reported an antioxidant-rich decoction Pelargonium graveolens containing a water-soluble polysaccharide (Ennaifer, Bouzaine, Chouaibi, \& Hamdi, 2018). Also, Zhang et al., (2019) isolated three polysaccharide extract with and without proteins and found that the protein-containing polysaccharide extract exhibited the highest antioxidant activity (Zhang et al., 2019). In another study, Huang et al., (2003) reported that polysaccharides isolated from Cordyceps sinesis showed no antioxidant activity following separation of the protein from the crude (Huang, Liang, Guo, Zhou, \& Cheng, 2003). In addition, Siu et al., (2016) investigated the antioxidant activities of crude polysaccharide from mushrooms (L. edodes, G. frondosa, and Zt. Versicolor) and found that their antioxidant activities were positively correlated with the contents of phenolic acids and proteins ( $\mathrm{Siu}, \mathrm{Xu}, \mathrm{Chen}, \& \mathrm{Wu}, 2016$ ). Indeed, the formation of polysaccharide complexes with other components such as amino acids, proteins, and lipids are particularly common, yielding polysaccharide conjugates. Interestingly, majority of reports indicate that the polysaccharide conjugates exhibit higher antioxidant activities than the free polysaccharides or bioactive compounds. It has been suggested that polysaccharide-polyphenols and polysaccharide-protein conjugates are formed via hydrophobic interactions and hydrogen bonding. Recently Barmudez et al., (2019) reported that interactions between polysaccharides and phenolic compounds contributed to a strong free radical scavenging activity through a combination of covalent (ester bonds) and non-covalent (hydrogen bonding and electrostatic interactions) interactions (Barmuez et al., 2019). It was found that the interactions after drying were stronger than those found in the simple mixture. For example, phenolic acids (secondary metabolites in many plant species) form polysaccharide conjugates that exhibit significant antioxidant activities. Indeed, Wang et al., (2012) investigated the antioxidant activities of oolong tea and found no antioxidant activities from the phenolic acid-free and protein-free extracts (Wang, Yang, \& Wei, 2012).

Polyphenol associated polysaccharides are also known to contribute significantly to the antioxidant activity determined by using the DPPH assay. In some cases, polyphenol-free tea polysaccharides have also been found to exhibit a strong antioxidant activity. Thus, to examine the role of polysaccharide polyphenol complexes in determining the antioxidant activity of such species, Wu et al., (2011) carried out a comparative study using tea polyphenols, $\beta$-glucan, and the corresponding mixture and complex, and found that the complex exhibited the highest antioxidant activity against hydroxyl free radicals (Wu et al., 2011). However, inconsistent results were found for the mixture, thereby demonstrating that a complex structure of tea polyphenols and $\beta$-glucan plays a critical role in determining the antioxidant activity. Ferulic acid polysaccharide complexes have also been found to exhibit strong antioxidant activities. Moreover, Shu et al., (2019) investigated the role of particle size in green tea powder and found that the antioxidant activity could be improved by reducing the particle size (Shu, Li, Yang, Dong, Wang, 2019).

Selenium is a biologically relevant element found in soil and agricultural products. However, organoselenium compounds have been reported to exhibit more beneficial properties than free selenium species. To mimic the enhanced bioavailability and biological properties of organoselenium compounds, a series of selenium compounds have been synthesized using biologically relevant molecules such as proteins, amino acids, alkaloids and polysaccharides. For example, Wei et al. (2012) reported that a selenylated polysaccharide (Se- RHP) synthesized from Radix hedysari exhibited an enhanced antioxidant activity compared to the free polysaccharide (Wei, Cheng, Wei, \& Zhang, 2012). Similar polysaccharide selenium complexes have been synthesized by Wang et al., (2012) using a polysaccharide extracted from Artemisia sphaerocephala (Wang, Zhao, Wang, Yao, \& Zhao, 2012). In addition, in the case of Potentilla anserina L. Zhao et al., (2013) successfully improved the antioxidant activity compared to the native polysaccharides through the formation of a complex with selenium (Zhao et al., 2013). The higher antioxidant activity of the polysaccharide was attributed to conformational changes in the polymers containing a higher number of hydroxyl groups. Furthermore, Yu et al., (2007) reported that Se-enriched green tea had a higher antioxidant activity than the regular tea due to the formation of polysaccharide-Se complexes, while polysaccharides isolated from Se-enriched G. lucidum were more effective in reducing the production of superoxide radicals ( Yu , Sheng, Xu, An, \& Hu, 2007; Zhao et al., 2008). Moreover, Mao et al., (2014) and Cheng et al., (2013) studied the polysaccharide isolated from G. frondosa and found that the Se-enriched polysaccharide (Se-GP) was a stronger scavenger for DPPH, ABTS, and hydroxyl 
radicals (Mao et al., 2014; Cheng et al., 2013). However, no significant differences were observed between these species in terms of the polysaccharide content and the molecular weight, with the Se content being the only variable. Interestingly, Guo et al., (2013) reported that a selenium-polysaccharide synthesized by using selenium chloride oxide $\left(\mathrm{SeCl}_{2} \mathrm{O}\right)$ and the polysaccharide also exhibited a higher total antioxidant capacity, superoxide radical scavenging effect, and hydroxyl radical scavenging effect (Guo et al., 2013).

\subsection{Antioxidant Properties of Processed Polysaccharide}

The biological properties of polysaccharide are dependent on their structural composition, conformation, and type of glycosidic linkage. Moreover, the sources, extraction, and processing methods, significantly influence the polysaccharide structure and conformation, which can subsequently alter the chemical and biological properties. Interestingly, number of reports have indicated a correlation between the molecular weight and radical scavenging activity of polysaccharides (Liu, Wang, Pang, Yao, \& Gao, 2010; Xing et al., 2005; Zha et al., (2009); Sun, Wang, Shi, \& Ma, 2009; Zhang, Wang, Mo, \& Qi, 2013, Choi et al., 2009). It was hypothesized that polysaccharides with low molecular weights would possess a greater number of reductive hydroxyl group terminals to accept and eliminate free radicals, since the number of hydroxyl or amino groups in polysaccharide molecules such as chitosan greatly influence the free radical scavenging activity. For example, Zhang et al., (2019) isolated four polysaccharide fractions (P-1: 71.40\%, P-2: 1.95\%, P-3: 1.14\%, and P-4: 1.64\%) from crude Polygonatum sibiricum polysaccharide (PSP), and the antioxidant capacity was P-4 > P-3 > P-2 > PSP > P-1 (Zhang et al., 2019). In addition, two low molecular weight polysaccharides were isolated from G. lucidum by Liu et al., (2010) and these were reported to display significant antioxidant activities (Liu, Wang, Pang, Yao, \& Gao, 2010). Similarly, Xing et al., (2005) observed higher scavenging activities by polysaccharides with lower molecular weights, which was partly attributed to differences in their structural composition compared with higher molecular weight species (Xing et al., 2005). Furthermore, Zha et al.(2009) obtained three polysaccharide fractions from rice bran with molecular weights ranging from $1.2 \times 10^{5}$ to $6.3 \times 10^{6} \mathrm{Da}$ (PW1), $3.5 \times 10^{4}$ to $7.4 \times$ $10^{4} \mathrm{Da}$ (PW2), and $5.3 \times 10^{3}$ to $2.3 \times 10^{4} \mathrm{Da}$ (PW3), and they found that PW3 exhibited the best reducing power, chelating metal ion potential, and scavenging ability against DPPH and ABTS radicals (Zha et al., 2009).

To improve the taste and quality of raw materials for foodstuffs, processing is commonly carried out using a range of methods, including cooking. During such processing, polysaccharides are transformed or degraded; for example, treatment with $\gamma$-rays enhances the antioxidant activity as the polysaccharide structure is retained, but fragmentation to lower molecular weight polysaccharides took place (Choi et al., 2009). Treatment with ultrasonic waves also degrades the polysaccharide structure and enhances the antioxidant activity (Zhou, Wang, $\mathrm{Ma}, \& \mathrm{He}, 2008$ ). In addition, various chemical treatment methods have been adopted for the processing of foods, including the use of ascorbic acid and hydrogen peroxide to degrade the polysaccharide obtained from Enteromorpha linza. (Zhang, Wang, Zhao, \& Qi, 2014). However, contrasting results were obtained. More specifically, although Sun et al., (2009) reported that high molecular weight polysaccharides exhibited no significant antioxidant activities, and low molecular weight polysaccharides displayed strong antioxidant activities (Sun, Wang, Shi, \& Ma, 2009). Cheng et al., (2013) found that higher molecular weight polysaccharides from Epimedium acuminatum exhibited higher antioxidant activities than the lower molecular weight polysaccharides (Cheng et al., 2013). In contrast, some other studies have suggested that the effect of molecular weight was not significant based on the similar antioxidant levels of polysaccharides and oligosaccharides (Kardosova \& Machov, 2006).

\subsection{Antioxidant Activities of Functionalized Polysaccharides and Polysaccharides Bearing Different Functional Groups}

The structural characteristics of a polysaccharide play a significant role in determining its potential antioxidant activity. Although polysaccharides bearing only an oxygen heteroatom do not exhibit significant antioxidant properties derivatization through sulfation, carboxylation, phosphorylation, benzoylation, acetylation, or oxidation produces promising antioxidants. For example, sulfated polysaccharides are major derivatives that exhibit significant antioxidant activities and protect against lipid peroxidation. Yang et al., (2011) confirmed that the sulfated polysaccharides from Corallina officinalis displayed a higher antioxidant potential than the desulafated species (Yang, Liu, Wu, \& Chen, 2011). A similar observation was reported by Hu et al., (2010) for the polysaccharides extracted from Undaria pinnatifida, while Wang et al., ((2009) reported that native sulfated polysaccharides isolated from Laminaria japonica showed a significant antioxidant activity (Hu, Liu, Chen, Wu, 2010; Wang et al., 2009). Indeed, it has been reported that the antioxidant capacity of a sulfated polysaccharide depends on the degree of substitution on the polysaccharide backbone, since the degree of substitution has a critical impact on polymer conformational and structural changes. In addition, Qi et al., (2015) isolated four different polysaccharides with varied molecular weight and reported that low molecular weight polysaccharides 
had a higher reducing power (Qi et al., 2005). Furthermore, Zhang et al.,(2011) reported a strong antioxidant activity for the sulfated polysaccharide isolated from fresh persimmon (Diospyros kaki L.) fruit, while Wu et al., (2013) reported the development of acetylated, phosphorylated, and benzoylated levan-type exopolysaccharide from Paenibacillus polymyxa EJS-3. Moreover, Wei et al., (2012) modified phosphorylated polysaccharides from Radix hedysari, while Qi et al., (2006) acetylated and benzoylated derivatives from the polysaccharides of Ulva pertusa. (Qi et al., 2006; Wei, Cheng, Wei, \& Zhang, 2012).

Pectic acid, chitosans and alginates are some other form of polysaccharides that exhibit high antioxidant activities. However due to the cationic or anionic nature of these polysaccharides, the presence of sulfated or phosphorylated glucans resulted in different antioxidant potentials (Qi et al., 2005). For example, Chen et al. (2009) reported that agar bearing a sulfate group, and chitosan bearing an amino group exhibited antioxidant activities, while starch bearing a hydroxyl group did not (Chen, Tsai, Huang \& Chen, 2009). In a similar study Rao and Muralikrishna observed that glucose and soluble starch, laminarin, did not show any antioxidant activity (Rao \& Muralikrishna, 2006). In addition, acidic polysaccharides containing uronic acid displayed a higher antioxidant activity due to the presence of electrophilic keto or aldehyde groups (Chen, Zhang, \& Xie, 2004). Interestingly, uronic acid polysaccharides exhibit a different levels of antioxidant properties, decreasing in the order polygalacturonic acid $>$ glucuronic acid $>$ galacturonic acid. This difference was attributed to the nature of the carbonyl group (i.e., chain or ring). Furthermore, $\mathrm{Li}$ et al. (2011) reported that polysaccharides isolated from Zizyphus Jujuba cv. Jinsixiaozao exhibited different antioxidant activities due to the presence of varying levels of uronic acid with polysaccharide fractions containing higher uronic acid contents giving stronger free radical scavenging activities than fractions containing no uronic acid (Li, Liu, Fan, Ai, \& Shan, 2011).

Fucoidan is a natural sulfated polysaccharide found in algae and it has been shown to have number of health benefits. Wang et al. (2009) extracted fucoidan from Laminaria japonica and derivatized it to its sulfated, phosphorylated, benzoylated and aminated forms, all of which exhibited strong antioxidant activities (Wang et al., 2009). In addition, Feng et al., (2010) modified the lentinan polysaccharide found in mushrooms to give its sulfated derivative, which again exhibited a significant antioxidant activity (Feng, $\mathrm{Li}, \mathrm{Wu}, \mathrm{He}, \& \mathrm{Ma}, 2010$ ). Compared to the native polysaccharide extracted from Portulaca oleracea L. Chen et al., (2014) reported that phosphorylated polysaccharides produced higher antioxidant activities (Chen et al., 2014). In addition, Wang et al., (2014) phosphorylated the galactomannan polysaccharide and found that a higher degree of phosphorylation correlated positively with the antioxidant activity (Wang et al., 2014). Furthermore, Jung et al., (2011) reported higher antioxidant activity upon increasing the degree of sulfation, while Wang et al., (2013) found that a higher degree of sulfation in the polysaccharide isolated from the green algae Enteromorpha linza gave a higher DPPH scavenging activity (Jung, Bae, Lee, \& Lee, 2011; Wang et al., 2013). In contrast, Xie et al., (2015) found that sulfated polysaccharides with the highest degree of substitution did not produce the highest antioxidant activities.

Based on these results for functionalized polysaccharides it was hypothesized that substitution on a polysaccharide chain weakens the dissociation energy of the hydrogen bonds, and so the hydrogen donating ability of the polysaccharide derivatives is greater than that of the unmodified species. Alternatively, abstraction from the anomeric carbon may be promoted. However, chemical modification is often accompanied by a decrease in molecular weight, thereby improving the antioxidant potentials of the polysaccharides. In terms of sulfated polysaccharides, free radicals are often trapped in an electrostatic manner since the sulfate groups tend to generate a highly acidic environment, while substitution by sulfur may also weaken the hydrogen bonding between polysaccharides (Wang et al., 2016). Furthermore, the types of substitution and the degree of substitution appeared to influence the physicochemical properties (e.g. molecular weight, polarity, solubility, and charge density) and conformation of native polysaccharides. The degree of substitution may also affect the activity through interruption of the inter and intramolecular hydrogen bonds (Wang et al., 2016). It is also possible that saccharides (carbohydrates) can become antioxidants in alkaline media at $\mathrm{pH}$ values $>9$. In such a medium, an amperometric sensor can directly detect saccharides without the requirement for derivatization, thereby selecting only the target antioxidants (Wang, Zhang, Yao, Zhao, \& Qi, 2013). Moreover, in an alkaline medium, dissociation occurs through the removal of hydrogen from the hydroxyl groups of saccharides. This does not take place in other media (acid and/or neutral), and so in such cases, the amperometric sensor does not detect the presence of any saccharides.

Antioxidant activities of polysaccharide have been associated with diverse forms of polysaccharide including polysaccharide conjugate, polysaccharide complex, functionalized polysaccharide and degraded products of polysaccharide (Figure 2). In addition to the significant antioxidant properties of polysaccharides, these macromolecular systems also exhibit anticancer and antiviral properties, immune regulation and other biological activities. More specifically, the anti-cancer properties of polysaccharides have been reported to occur through 
either the induction of cellular apoptosis and cell cycle arrest, or by inhibiting tumor invasion, adhesion and metastasis. In addition, synergistic effects have been reported in combination treatment with conventional anti-cancer drugs (Chen \& Huang, 2018; Lovegrove et al., 2017). Polysaccharides are known to play a significant role in human health, since the rate of digestion, adsorption, and metabolism of polysaccharides is regulated in the stomach, small intestine, and large intestine thereby controlling colonic health and vascular function. Dietary polysaccharides therefore have the potential to regulate the intestinal microenvironmentand stimulate macrophages or lymphocytes in the gut tissues to prevent cancers (Huang, Nie, \& Xie, 2017; Laurienzo, 2010). Dietary fiber and resistant forms of starch therefore play a positive role in reducing risk factors for chronic diseases, including cardiovascular disease and certain types of cancers.

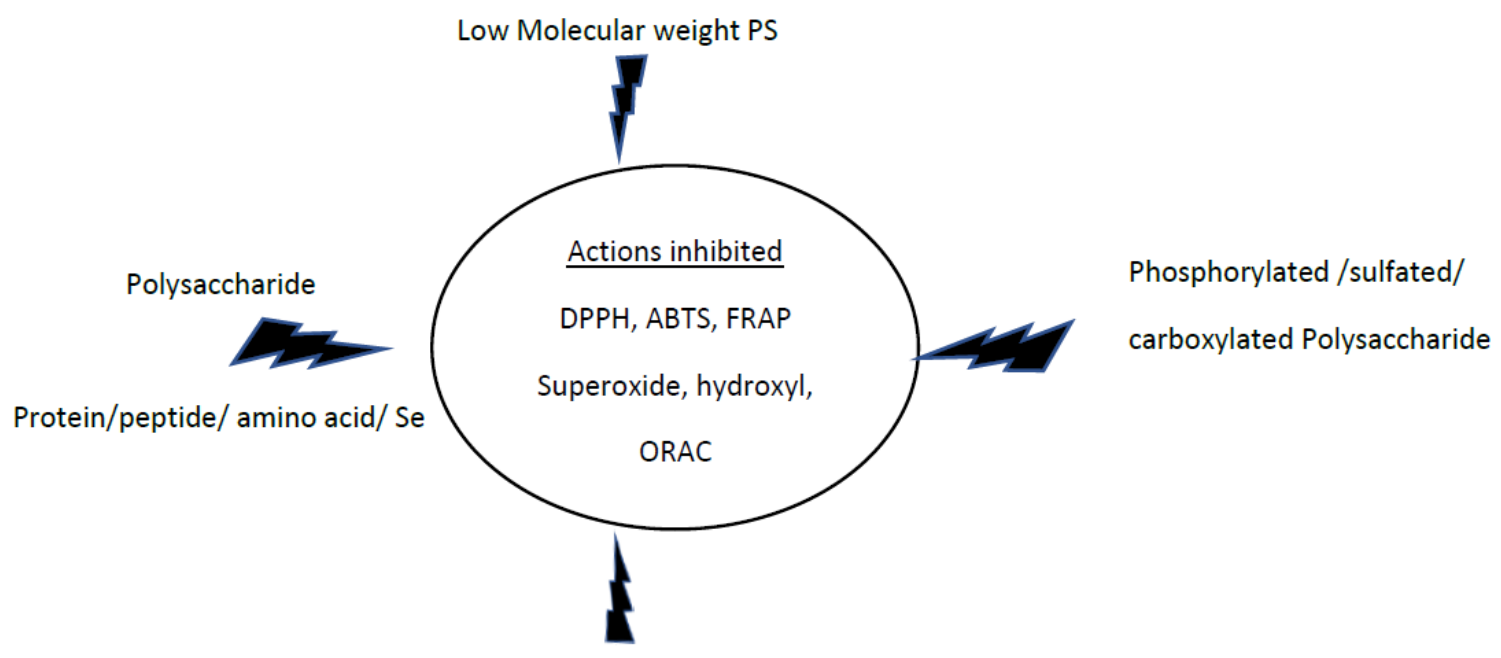

Polysaccharide polyphenol complex

Figure 2. Polysaccharide species for antioxidant activities

\section{Conclusion}

Natural antioxidants exhibiting strong antioxidant activities are commonly employed to protect against oxidative damage, yet little is known regarding the antioxidant effects of polysaccharides. Although polysaccharide-rich foodstuffs assigned a high glycemic index (i.e. rapidly digested to give glucose) suspected to have links with obesity, diabetes, and high blood pressure, recent findings into the physiological effects of polysaccharides, polysaccharide conjugates, and polysaccharide complexes with biorelevant molecules results in slower glucose release and provides physiological health benefits. Therefore, modified polysaccharide and slowly digested polysaccharides are the most desirable types of polysaccharides from a nutritional standpoint. We expect that recent findings into polysaccharides exhibiting antioxidant properties may lead to a better understanding of the potential of natural polysaccharides to act as functional antioxidants, due to their high antioxidant activities. This area is therefore in need of further exploration in future studies.

\section{References}

Alzorqi, I., Sudheer, S., Lu, T. J., \& Manickam, S. (2016). Ultrasonically extracted $\beta$-D-glucan from artificially cultivated mushroom, characteristic properties and antioxidant activity. Ultrasonics Sonochemistry, 35, 531-540. https://doi.org/10.1016/j.ultsonch.2016.04.017

Bermúdez-Oria, A., Rodríguez-Gutiérrez, G., Fernández-Prior, Á., Vioque, B., \& Fernández-Bolaños, J. (2019). Strawberry dietary fiber functionalized with phenolic antioxidants from olives. Interactions between polysaccharides and phenolic compounds. Food Chemistry, 280, 310-320. https://doi.org/10.1016/j.foodchem.2018.12.057

Cazón, P., Velazquez, G., Ramírez, J. A., \& Vázquez, M. (2017). Polysaccharide-based films and coatings for food packaging: A review. Food Hydrocolloids, 68, 136-148.

Chen, L., \& Huang, G. (2018). Antitumor activity of polysaccharides- An overview. Current Drug Targets, 19 , 89-96. https://doi.org/10.2174/1389450118666170704143018

Chen, X., Zhong, H., Zeng, J., \& Ge, J. (2008). The pharmacological effect of polysaccharides from Lentinus 
edodes on the oxidative status and expression of VCAM-1mRNA of thoracic aorta endothelial cell in high-fat-diet rats. Carbohydrate Polymers, 74(3), 445-450.

Chen, J., \& Huang, G. (2019). Antioxidant activities of garlic polysaccharide and its phosphorylated derivative. International Journal of Biological Macromolecules, 125, 432-435. https://doi.org/10.1016/j.ijbiomac.2018.12.073

Chen, L., \& Huang, G. (2019). Antioxidant activities of sulfated pumpkin polysaccharides. International Journal of Biological Macromolecules, 126, 743-746. https://doi.org/10.1016/j.ijbiomac.2018.06.148

Chen, F., \& Huang, G. (2018). Extraction and antioxidant activities of cushaw polysaccharide. International Journal of Biological Macromolecules, 1646-1649. https://doi.org/10.1016/j.ijbiomac.2018.09.200

Chen, Y., Zhang, H., Wang, Y., Nie, S., Li, C., \& Xie, M. (2014). Acetylation and carboxymethylation of the polysaccharide from Ganoderma atrum and their antioxidant and immunomodulating activities. Food Chemistry, 156, 279-288. https://doi.org/10.1016/j.foodchem.2014.01.111

Chen, H. X., Zhang, M., \& Xie, B. J. (2004). Quantification of uronic acids in tea polysaccharide conjugates and their antioxidant properties. Journal of Agricultural and Food Chemistry, 52, 3333-3336. https://doi.org/10.1021/jf0349679

Chen, F., \& Huang, G. (2019). Antioxidant activity of polysaccharides from different sources of ginseng. International Journal of Biological Macromolecules, 125, 906-908. https://doi.org/10.1016/j.ijbiomac.2018.12.134

Chen, R., Jin, C., Tong, Z., Lu, J., Tan, L., Tian, L., \& Chang, Q. (2016). Optimization extraction, characterization and antioxidant activities of pectic polysaccharide from tangerine peels. Carbohydrate Polymers, 136, 187-197. https://doi.org/10.1016/j.carbpol.2015.09.036

Chen, S. K., Tsai, M. L., Huang, J. R., \& Chen, R. H. (2009). In vitro antioxidant activities of low-molecular-weight polysaccharides with various functional groups. Journal of Agricultural and Food Chemistry, 57, 2699-2704. https://doi.org/10.1021/jf804010w

Cheng, H., Feng, S., Shen, S., Zhang, L., Yang, R., Zhou, Y., \& Ding, C. (2013). Extraction, antioxidant and antimicrobial activities of Epimedium acuminatum Franch. Polysaccharide. Carbohydrate Polymers, 96, 101-108. https://doi.org/10.1016/j.carbpol.2013.03.072

Cheng, J. H., Tsai, C. L., Lien, Y. Y., Lee, M. S., \& Sheu, S. C. (2016). High molecular weight of polysaccharides from Hericium erinaceus against amyloid $\beta$-induced neurotoxicity. BMC Complementary and Alternative Medicine, 16, 170. https://doi.org/10.1186/s12906-016-1154-5

Choi, J. I., Kim, H. J., Kim, J. H., Byun, M. W., Soo, C. B., Hyun, A. D., Hwang, Y., J., Kim, D. J., \& Lee, J., W. (2009). Application of gamma irradiation for the enhanced physiological properties of polysaccharides from seaweeds. Applied Radiation and Isotopes, 67, 1277-1281. https://doi.org/10.1016/j.apradiso.2009.02.027

Copeland, L., Blazek, J., Salman, H., \& Tang, M. C. (2009). Form and functionality of starch. Foods Hydrocolloids, 23(6), 1527-1534. https://doi.org/10.1016/j.foodhyd.2008.09.016

Cui, S. W. (2005). Food Carbohydrates: chemistry, physical properties, and applications, CRC Press.

Ennaifer, M., Bouzaiene, T., Chouaibi, M., \& Hamdi, M. (2018). Pelargonium graveolens aqueous decoction: a new water-soluble polysaccharide and antioxidant-rich extract. Biomedical Research International, 12, 2691513. https://doi.org/10.1155/2018/2691513

Feng, K., Chen, W., Sun, L., Liu, J., Zhao, Y., Li, L., Wang, Y., \& Zhang, W. (2015). Optimization extraction, preliminary characterization and antioxidant activity in vitro of polysaccharides from Stachys sieboldii Miq. tubers. Carbohydrate Polymers, 125, 45-52. https://doi.org/10.1016/j.carbpol.2015.02.026

Feng, Y., Li, W., Wu, X., He, L, \& Ma, S. (2010). Rapid and efficient microwave-assisted sulfate modification of lentinan and its antioxidant and antiproliferative activities in vitro. Carbohydrate Polymers, 82, 605-612. https://doi.org/10.1016/j.carbpol.2010.05.025

Guo, S., Mao, W., Han, Y., Zhang, X., Yang, C., Chen, Y., Chen, Y., Xu, J., Li, H., Qi, X., \& Xu, J. (2010). Structural characteristics and antioxidant activities of the extracellular polysaccharides produced by marine bacterium Edwardsiella tarda. Bioresource Technology, 101(12), 4729-4732. https://doi.org/10.1016/j.biortech.2010.01.125

Guo, Y., Pan, D., Li, H., Sun, Y., Zeng, X., \& Yan, B. (2013). Antioxidant and immunomodulatory activity of 
selenium exopolysaccharide produced by Lactococcus lactis subsp. Lactis. Food Chemistry, 138, 84-89. https://doi.org/10.1016/j.foodchem.2012.10.029

Han, X., Shen, S., Liu, T., Du, X., Cao, X., Feng, H., \& Zeng, X. (2015). Characterization and antioxidant activities of the polysaccharides from Radix Cyathulae officinalis Kuan. International Journal of Biological. Macromolecules, 72, 544-552. https://doi.org/10.1016/j.ijbiomac.2014.09.007

Han, Q. H., Liu, W., Li, H. Y., He, J. L., Guo, H., Lin, S., Zhao, L., Chen, H., Liu, Y. W., Wu, D. T., Li, S. Q., \& Qin, W. (2019). Extraction optimization, physicochemical characteristics, and antioxidant activities of polysaccharides from Kiwifruit (Actinidia chinensis Planch.). Molecules, 24(3), 461. https://doi.org/10.3390/molecules24030461

Hajji, M., Hamdi, M., Sellimi, S., Ksouda, G., Laouer, H., Li, S., \& Nasri, M. (2019). Structural characterization, antioxidant and antibacterial activities of a novel polysaccharide from Periploca laevigata root barks. Carbohydrate Polymers, 206, 380-388. https://doi.org/10.1016/j.carbpol.2018.11.020

Huang, Q. L., Siu, K. C., Wang, W. Q., Cheung, Y. C., \& Wu, J. Y. (2013). Fractionation, characterization and antioxidant activity of exopolysaccharides from fermentation broth of a Cordyceps sinensis fungus. Process Biochemistry, 48(2), 380-386. https://doi.org/10.1016/j.procbio.2013.01.001

Huang, L. F., Liang, Y. Z., Guo, F. Q., Zhou, Z. F., \& Cheng, B. M. (2003). Simultaneous separation and determination of active components in Cordyceps sinensis and Cordyceps militaris by LC/ESI-MS. Journal of Pharmaceutical and Biomedical Analysis, 33, 1155-1162. https://doi.org/10.1016/s0731-7085(03)00415-1

Huang, X., Nie, S., \& Xie, M. (2017). Interaction between gut immunity and polysaccharides. Critical Reviews in Food Science and Nutrition, 57, 2943-2955. https://doi.org/10.1080/10408398.2015.1079165

Hu, J. F., Gen, M. Y., Zhang, J. T., \& Jiang, H. D. (2001). An in vitro study of the structure-activity relationships of sulfated polysaccharide from brown algae to its antioxidant effect. Journal of Asian Natural Product Research, 3(4), 353-358. https://doi.org/10.1080/10286020108040376

Hui, Y., Jun-Li, H., \& Chuang, W. (2019). Anti-oxidation and antiaging activity of polysaccharide from Malus micromalus Makino fruit wine. International Journal of Biological. Macromolecules, 121, 1203-1212. https://doi.org/10.1016/j.ijbiomac.2018.10.096

Hu, C., Li, J., Yang, D., Pan, Y., \& Wan, H. (2010). A neuroprotective polysaccharide from Hyriopsis cumingii. Journal of Natural Products, 73(9), 1489-1493. https://doi.org/10.1021/np1001847

Hu, Y., Sheng, Y., Yu, M., Li, K., Ren, G., Xu, X., \& Qu, J. (2016). Antioxidant activity of Inonotus obliquus polysaccharide and its amelioration for chronic pancreatitis in mice. International Journal of Biological. Macromolecules, 87, 348-56. https://doi.org/10.1016/j.ijbiomac.2016.03.006

Hu, T., Liu, D., Chen, Y., Wu, J., \& Wang, S. (2010). Antioxidant activity of sulfated polysaccharide fractions extracted from Undaria pinnitafida in vitro. International Journal of Biological Macromolecules, 46, 193-198. https://doi.org/10.1016/j.ijbiomac.2009.12.004

Jiang, Y. Y., Yu, J., Li, Y. B., Wang, L., Hu, L., Zhang, L., \& Zhou, Y. H. (2019). Extraction and antioxidant activities of polysaccharides from roots of Arctium lappa L. International Journal of Biological Macromolecules, 123, 531-538. https://doi.org/10.1016/j.ijbiomac.2018.11.087

Jiang, C., Li, X., Jiao, Y., Jiang, D., Zhang, L., Fan, B., \& Zhang, Q. (2014). Optimization for ultrasound-assisted extraction of polysaccharides with antioxidant activity in vitro from the aerial root of Ficus microcarpa. Carbohydrate Polymers, 110, 10-17. https://doi.org/10.1016/j.carbpol.2014.03.027

Jung, H. Y., Bae, I., Lee, Y. S., \& Lee, H. G. (2011). Effect of the degree of sulfation on the physicochemical and biological properties of Pleurotus eryngii polysaccharides. Food Hydrocolloids, 25, 1291-1295. https://doi.org/10.1016/j.foodhyd.2010.12.002

Kardo`sov'a, A., \& Machov`a, E. (2006). Antioxidant activity of medicinal plant polysaccharides. Fitoterapia, 77, 367-373. https://doi.org/10.1016/j.fitote.2006.05.001

Kodali, V. P., \& Sen, R. (2008). Antioxidant and free radical scavenging activities of an exopolysaccharide from a probiotic bacterium. Biotechnology Journal, 3(2), 245-251.

Kong, F., Mingwei, Z., Sentai, L., Shujuan, Y., Jianwei, C., \& Zhencheng, W. (2010). Antioxidant activity of polysaccharide-enriched fractions extracted from pulp tissue of Litchi Chinensis Sonn. Molecules, 15(4), 2152-2165. https://doi.org/10.3390/molecules 15042152 
Laurienzo, P. (2010). Marine Polysaccharides in Pharmaceutical Applications: An Overview. Marine Drugs, 8(9), 2435-2465. https://doi.org/10.3390/md8092435

Lima, A. T., Santos, M. N., de Souza, L. A., Pinheiro, T. S., Paiva, A. A., Dore, C. M., ... Araujo, R. M. (2016). Chemical characteristics of a heteropolysaccharide from Tylopilus ballouii mushroom and its antioxidant and anti-inflammatory activities. Carbohydrate Polymers, 144, 400-409. https://doi.org/10.1016/j.carbpol.2016.02.050

Liu, F., Ooi, V. E. C., \& Chang, S. T. (1997). Free radical scavenging activities of mushroom polysaccharide extracts. Life Sciences, 60, 763-771. https://doi.org/10.1016/s0024-3205(97)00004-0

Liu, W., Wang, H., Pang, X., Yao, W., \& Gao, X. (2010). Characterization and antioxidant activity of two low-molecular-weight polysaccharides purified from the fruiting bodies of Ganoderma lucidum, International. Journal of Biological Macromolecules, 46, 451-457. https://doi.org/10.1016/j.ijbiomac.2010.02.006

Li, J., Liu, Y., Fan, L., Ai, L., \& Shan, L. (2011). Antioxidant activities of polysaccharides from the fruiting bodies of Zizyphus Jujuba cv. Jinsixiaozao. Carbohydrate Polymers, 84, 390-394. https://doi.org/10.1016/j.carbpol.2010.11.051

Lovegrove, A., Edwards, C. H., De Noni, I., Patel, H., El, S. N., Grassby, T., ... Shewry, P. R. (2017). Role of polysaccharides in food, digestion, and health, Critical Reviews in Food Science and Nutrition, 57, 237-253. https://doi.org/10.1080/10408398.2014.939263

Maity, G. N., Maity, P., Dasgupta, A., Acharya, K., Dalai, S., \& Mondal, S. (2019). Structural and antioxidant studies of a new arabinoxylan from green stem Andrographis paniculata (Kalmegh). Carbohydrate Polymers, 212, 297-303. https://doi.org/10.1016/j.carbpol.2019.02.051

Maity, P., Sen, I. K., Maji, P. K., Paloi, S., Devi, K. S. P., Acharya, K., Maiti, T. K., \& Islam, S. S. (2015). Structural, immunological, and antioxidant studies of $\beta$-glucan from edible mushroom Entoloma lividoalbum. Carbohydrate Polymers, 123, 350-358. https://doi.org/10.1016/j.carbpol.2015.01.051

Mao, G., Zou, Y., Feng, \& W., Wang, W., Zhao, T., Ye, C., Zhu, Y., Wu, X., Yang, L., \& Wu, X. (2014). Extraction, preliminary characterization and antioxidant activity of Se-enriched Maitake polysaccharide. Carbohydrate Polymers, 101, 213-219. https://doi.org/10.1016/j.carbpol.2013.09.034

Mu, H., Zhang, A., Zhang, W., Cui, G., Wang, S., \& Duan, J. (2012). Antioxidative properties of crude polysaccharides from Inonotus obliquus. International Journal of Molecular Sciences, 13, 9194-9206. https://doi.org/10.3390/ijms13079194

Ngo, D. N., Kim, M. M., \& Kim, S. K. (2008). Chitin oligosaccharides inhibit oxidative stress in live cells. Carbohydrate Polymers, 74(2), 228-234. https://doi.org/10.1016/j.carbpol.2008.02.005

Pan, S., \& Wu, S. (2014). Cellulase-assisted extraction and antioxidant activity of the polysaccharides from garlic. Carbohydrate Polymers, 111, 606-609. https://doi.org/10.1016/j.carbpol.2014.05.022

Qiao, D., Ke, C., Hu, B., Luo, J., Ye, H., Sun, Y., Yan, X., \& Zeng, X. (2009). Antioxidant activities of polysaccharides from Hyriopsis cumingii. Carbohydrate Polymers, 78(2), 199-204. https://doi.org/10.1016/j.carbpol.2009.03.018

Qi, H., Zhang, Q., Zhao, T., Hu, R., Zhang, K., \& Li, Z. (2006). In vitro antioxidant activity of acetylated and benzoylated derivatives of polysaccharide extracted from Ulva pertusa (Chlorophyta). Bioorganic and Medicinal Chemistry Letters, 16, 2441-2445. https://doi.org/10.1016/j.bmcl.2006.01.076

Qi, H., Zhao, T., Zhang, Q., Li, Z., Zhao, Z., \& Xing, R. (2005). Antioxidant activity of different molecular weight sulfated polysaccharides from Ulva pertusa Kjellm (Chlorophyta). Journal of Applied Physics, 17, 527-534. https://doi.org/10.1007/s10811-005-9003-9

Raza, W., Makeen, K., Wang, Y., Xu, Y., \& Qirong, S. (2011). Optimization, purification, characterization and antioxidant activity of an extracellular polysaccharide produced by Paenibacillus polymyxa SQR-21. Bioresource Technology, 102(10), 6095-6103. https://doi.org/10.1016/j.biortech.2011.02.033

Rao, R. S. P., \& Muralikrishna, G. (2006). Water soluble feruloyl arabinoxylans from rice and ragi: changes upon malting and their consequence on antioxidant activity. Phytochemistry, 67, 91-99. https://doi.org/10.1016/j.phytochem.2005.09.036

Ren, Q., Chen, J., Ding, Y., Cheng, J., Yang, S., Ding, Z., Dai, Q., \& Ding, Z. (2019). In vitro antioxidant and immunostimulating activities of polysaccharides from Ginkgo biloba leaves. International Journal of 
Biological Macromolecules, 124, 972-980. https://doi.org/10.1016/j.ijbiomac.2018.11.276

Rozi, P., Abuduwaili, A., Mutailifu, P., Gao, Y., Rakhmanberdieva, R., AkberAisa, H., \& Yili, A. (2019). Sequential extraction, characterization and antioxidant activity of polysaccharides from Fritillaria pallidiflora Schrenk, Intenational Journal of Biological Macromolecules, 131, 97-106. https://doi.org/10.1016/j.ijbiomac.2019.03.029

Shu, Y., Li, J., Yang, X., Dong, X., \& Wang, X. (2019). Effect of particle size on the bioaccessibility of polyphenols and polysaccharides in green tea powder and its antioxidant activity after simulated human digestion. Journal of Food Science and Technology, 56(3), 1127-1133. https://doi.org/10.1007/s13197-019-03573-4

Siu, K. C., Xu, L., Chen, X., \& Wu, J. Y. (2016). Molecular properties and antioxidant activities of polysaccharides isolated from alkaline extract of wild Armillaria ostoyaemushrooms. Carbohydrate Polymers, 137, 739-746. https://doi.org/10.1016/j.carbpol.2015.05.061

Sokolova, E. V., Barabanova, A. O., Homenko, V. A., Solov'eva, T. F., Bogdanovich, R. N., \& Yermak, I. M. (2011). In vitro and ex vivo studies of antioxidant activity of carrageenans, sulfated polysaccharides from red algae. Bulletin of Experimental Biology and Medicine, 150(4), 426-428. https://doi.org/10.1007/s10517-011-1159-5

Sun, Y., Wang, H., Guo, G., Pu, Y., \& Yan, B. (2014). The isolation and antioxidant activity of polysaccharides from the marine microalgae Isochrysis galbana. Carbohydrate Polymers, 113, 22-31. https://doi.org/10.1016/j.carbpol.2014.06.058

Sun, L., Wang, C., Shi, Q., \& Ma, C. (2009). Preparation of different molecular weight polysaccharides from Porphyridium cruentum and their antioxidant activities. International Journal of Biological Macromolecules, 45, 42-47. https://doi.org/10.1016/j.ijbiomac.2009.03.013

Tan, L. H., Zhang, D., Yu, B., Zhao, S. P., Wang, J. W., Yao, L., \& Cao, W. G. (2015). Antioxidant activity and optimization of extraction of polysaccharide from the roots of Dipsacus asperoides. International Journal of Biological Macromolecules, 81(10), 332-339. https://doi.org/10.1016/j.ijbiomac.2015.08.022

Tseng, Y. H., Yang, J. H., \& Mau, J. L. (2008). Antioxidant properties of polysaccharides from Ganoderma tsugae. Food Chemistry, 1072, 732-738. https://doi.org/10.3923/ijp.2011.58.65

Wang, J., Yang, T., Tian, J., Zeng, T., Wang, X., Yao, T., Zhang, J., \& Lei, Z. (2014). Synthesis and characterization of phosphorylated galactomannan: the effect of DS on solution conformation and antioxidant activities. Carbohydrate Polymers, 113, 325-335. https://doi.org/10.1016/j.carbpol.2014.07.028

Wang, J., Wang, F., Zhang, Q., Zhang, Z., Shi, X., \& Li, P. (2009). Synthesized different derivatives of low molecular fucoidan extracted from Laminaria japonica and their potential antioxidant activity in vitro. International Journal of Biological Macromolecules, 44, 379-384. https://doi.org/10.1016/j.ijbiomac.2009.02.001

Wang, J., Hu, S., Nie, S., Yu, Q., \& Xie, M. (2016). Reviews on mechanisms of in vitro antioxidant activity of polysaccharides Oxidative Medicine and Cellular Longetivity, 1-13. https://doi.org/10.1002/biot.200700208

Wang, H., Liu, Y. M., Qi, Z. M., Wang, S. Y., Liu, S. X., Li, X., Wang, H. J., \& Xia, X. C. (2013). An overview of natural polysaccharides with antioxidant properties. Current Medicinal Chemistry, 20, 2899-2913

Wang, N., Zhang, Y., Wang, X., Huang, X., Fei, Y., Yu, Y., \& Shou, D. (2016). Antioxidant property of water-soluble polysaccharides from Poria cocos Wolf using different extraction methods. International Journal of Biological Macromolecules, 83, 103-110. https://doi.org/10.1016/j.ijbiomac.2015.11.032

Wang, X., Zhang, Z., Wu, Y., Sun, X., \& Xu, N. (2019). Synthesized sulfated and acetylated derivatives of polysaccharide extracted from Gracilariopsis lemaneiformis and their potential antioxidant and immunological activity. International Journal Biological Macromolecules, 124, 568-572. https://doi.org/10.1016/j.ijbiomac.2018.11.244

Wang, X., Zhang, Z., Yao, Z., Zhao, M., \& Qi, H. (2013). Sulfation, anticoagulant and antioxidant activities of polysaccharide from green algae Enteromorpha linza. International Journal of Biological Macromolecules, 58, 225-230. https://doi.org/10.1016/j.ijbiomac.2013.04.005

Wang, Z., Zhao, Y., Su, T., Zhang, J., \& Wang, F. (2015). Characterization and antioxidant activity in vitro and in vivo of polysaccharide purified from Rana chensinensis skin. Carbohydrate Polymers, 126, 17-22. https://doi.org/10.1016/j.carbpol.2015.03.031 
Wang, Z., Zhao, Y., \& Su, T. (2015). Extraction and antioxidant activity of polysaccharides from Rana chensinensis skin. Carbohydrate Polymers, 115, 25-31. https://doi.org/10.1016/j.carbpol.2014.08.082

Wang, Y., Yang, Z., \& Wei, X. (2012). Antioxidant activities potential of tea polysaccharide fractions obtained by ultrafiltration. International Journal of Biological Macromolecules, 50, 558-564, 69. https://doi.org/10.1016/j.ijbiomac.2011.12.028

Wang, J., Zhao, B., Wang, X., Yao, J., \& Zhang, J. (2012). Synthesis of selenium-containing polysaccharides and evaluation of antioxidant activity in vitro. International Journal of Biological Macromolecules, 51(5), 987-991. https://doi.org/10.1016/j.ijbiomac.2012.08.011

Wei, E., Yang, R., Zhao, H., Wang, P., Zhao, S., Zhai, W., Zhang, Y., \& Zhou, H. (2019). Microwave-assisted extraction releases the antioxidant polysaccharides from seabuckthorn (Hippophae rhamnoides L.) berries. International Journal of Biological Macromolecules, 123, 280-290. https://doi.org/10.1016/j.ijbiomac.2018.11.074

Wei, D., Cheng, W., Wei, Y., \& Zhang, L. (2012). Phosphorylated modification and in vitro antioxidant activity of Radix hedysari polysaccharide. Glycoconjugate Journal, 29(4), 167-172. https://doi.org/10.3390/molecules22030501

Wu, Y., \& Wang, D. (2009). A new class of natural glycopeptides with sugar moiety-dependent antioxidant activities derived from Ganoderma lucidum fruiting bodies. Journal of Proteome Research, 8(2), 436-442. https://doi.org/10.1021/pr800554w

Wu, H., Zhu, J., Diao, W., \& Wang, C. (2014). Ultrasound-assisted enzymatic extraction and antioxidant activity of polysaccharides from pumpkin (Cucurbita moschata). Carbohydrate Polymers, 113, 314-324. https://doi.org/10.1016/j.carbpol.2014.07.025

Wu H., T. Min, X., Li, X. F., Li, L., Lai, F., Tang, Y. Q., \& Yang, X. H. (2013). Physicochemical properties and antioxidant activities of acidic polysaccharides from wampeeseeds. International Journal of Biological Macromolecules, 59, 90-95. https://doi.org/10.1016/j.ijbiomac.2013.04.020

Wu, Z., Zhang, M., Xie, M., Dai, Z., Wang, X., Hu, B., Ye, H., \& Zeng, X. (2016). Extraction, characterization and antioxidant activity of mycelial polysaccharides from Paecilomyces hepiali HN1. Carbohydrate Polymers, 137, 541-548. https://doi.org/10.1016/j.carbpol.2015.11.010

Wu, Z., Ming, J., Gao, R., Wang, Y., Linag, Q., Yu, H., \& Zhao, G. (2011). Characterization and antioxidant activity of the complex of tea polyphenols and oat $\beta$-glucan, Journal of Agricultural and Food Chemistry, 59(19), 10737-10746. https://doi.org/10.1021/jf202722w

Xie, J., Wang, Z., Shen, M., Nie, S. P., Gong, B., Li, H. S., Zhou, Q., Li, W. J., \& Xie, M. Y. (2015). Sulfated modification, characterization and antioxidant activities of polysaccharide from Cyclocarya paliurus. Food Hydrocolloids. https://doi.org/10.1016/j.foodhyd.2015.02.018

Xing, R., Liu, S., Guo, Z, Yu, H., Wang, P., Li, C., Li, Z., \& Li, P. (2005). Relevance of molecular weight of chitosan and its derivatives and their antioxidant activities in vitro. Bioorganic and Medicinal Chemistry, 13,1573-1577. https://doi.org/10.1016/j.bmc.2004.12.022

Xu, Y., Cai, F., Yu, Z., Zhang, L., Li, X., Yang, Y., \& Liu, G. (2016). Optimisation of pressurised water extraction of polysaccharides from blackcurrant and its antioxidant activity. Food Chemistry, 194, 650-658. https://doi.org/10.1016/j.foodchem.2015.08.061

Yao, Y., Zhu, Y., \& Ren, G. (2016). Antioxidant and immunoregulatory activity of alkali-extractable polysaccharides from mung bean. International Journal of Biological Macromolecules, 84, 289-94. https://doi.org/10.1016/j.ijbiomac.2015.12.045

Yang, L., \& Zhang, L. (2009). Chemical structural and chain conformational characterization of some bioactive polysaccharides isolated from natural sources. Carbohydrate Polymers, 76(3), 349-361. https://doi.org/10.1016/j.carbpol.2008.12.015

Yu, Y., Shen, M., Song, Q., \& Xie, J. (2018). Biological activities and pharmaceutical applications of polysaccharide from natural resources: A review. Carbohydrate Polymers, 183, 91-101. https://doi.org/10.1016/j.carbpol.2017.12.009

Yu, F., Sheng, J., Xu, J., An, X., \& Hu, Q. (2007). Antioxidant activities of crude tea polyphenols, polysaccharides and proteins of selenium-enriched tea and regular green tea. European. Food Research and Technology, 225, 843-848. https://doi.org/10.1007/s00217-006-0490-y 
Zeng, H., Zhang, Y., Zhao, Y., Tian, Y., Miao, S., \& Zheng, B. (2015). Extraction optimization, structure and antioxidant activities of Fortunella margarita Swingle polysaccharides. International Journal of Biological Macromolecules, 74, 232-242. https://doi.org/10.1016/j.ijbiomac.2014.12.013

Zha, X. Q., Wang, J. H., Yang, X. F., Liang, H., Zhao, L. L., Bao, S. H., Luo, J. P., Xu, Y. Y., \& Zhou, B. B. (2009). Antioxidant properties of polysaccharide fractions with different molecular mass extracted with hot-water from rice bran. Carbohydrate Polymers, 78, 570-575. https://doi.org/10.1016/j.carbpol.2009.05.020

Zhang, C., Zhao, F., Li, R., Wu, Y., Liu, S., \& Liang, Q. (2019). Purification, characterization, antioxidant and moisture-preserving activities of polysaccharides from Rosa rugosa petals. International Journal of Biological Macromolecules, 124, 938-945. https://doi.org/10.3390/molecules24071354

Zhang, L. S., Wang, X., \& Dong, L. L. (2011). Antioxidation and antiglycation of polysaccharides from Misgurnus anguillicaudatus. Food Chemistry, 124(1), 183-187.

Zhang, Z. S., Wang, F., Wang, X. M., Lie, X. L., Hou, Y, \& Zhang, Q. B. (2010). Extraction of the polysaccharides from five algae and their potential antioxidant activity in vitro. Carbohydrate Polymers, 82 , 118-121. https://doi.org/10.1016/j.carbpol.2010.04.031

Zhang, H., Cai, X. T., Tian, Q. H., Xiao, L. X., Zeng, Z., Cai, X. T., Yan, J. Z., \& Li, Q. Y. (2019). Microwave-assisted degradation of polysaccharide from Polygonatum sibiricum and antioxidant activity. Journal of Food Science, 84(4), 754-76. https://doi.org/10.1111/1750-3841.14449

Zhang, Z., Wang, X., Li, J., Wang, G., \& Mao, G. (2016). Extraction and free radical scavenging activity of polysaccharide from 'Anji Baicha' (Camellia sinensis (L.) O. Kuntze). International Journal of Biological Macromolecules, 84,161-165. https://doi.org/10.1016/j.ijbiomac.2015.12.016

Zhang, Z., Wang, X., Zhao, M., \& Qi, H. (2014). Free-radical degradation by Fe2+/Vc/H2O2 and antioxidant activity of polysaccharide from Tremella fuciformis. Carbohydrate Polymers, 112, 578-582.

https://doi.org/10.1016/j.carbpol.2014.06.030

Zhang, J. Q., Li, C., Huang, Q., You, L. J., Chen, C., Fu, X., \& Liu, R. H. (2019). Comparative study on the physicochemical properties and bioactivities of polysaccharide fractions extracted from Fructus Mori at different temperatures. Food and Function, 22, 10(1), 410-42. https://doi.org/10.1039/C8FO02190B

Zhang, Y., Lu, X., Fu, Z., Wang, Z., \& Zhang, J. (2011). Sulphated modification of a polysaccharide obtained from fresh persimmon (Diospyros kaki L.) fruit and antioxidant activities of the sulphated derivatives. Food Chemistry, 127, 1084-1090. https://doi.org/10.1016/j.foodchem.2011.01.100

Zhang, Z., Wang, X., Mo, X., \& Qi, H. (2013). Degradation and the antioxidant activity of polysaccharide from Enteromorpha linza. Carbohydrate Polymers, 92(2), 2084-2087.

https://doi.org/10.1016/j.carbpol.2012.11.096

Zhao, B., Zhang, J., Yao, J., Song, S., Yin, Z., \& Gao, Q. (2013). Selenylation modification can enhance antioxidant activity of Potentilla anserina L. polysaccharide. International Journal of Biological Macromolecules, 58, 320-328. https://doi.org/10.1016/j.ijbiomac.2013.04.059

Zhao, Y. M., Song, J. H., Wang, J., Yang, J. M., Wang, Z. B., \& Liu, Y. H. (2016). Optimization of cellulase-assisted extraction process and antioxidant activities of polysaccharides from Tricholoma mongolicum Imai. Journal of the Science of Food and Agriculture, 96, 4484-4491.

https://doi.org/10.1002/jsfa.7662

Zhao, L., Zhao, G., Du, M., Zhao, Z., Xia, L., \& Hu, X. (2008). Effect of selenium on increasing free radical scavenging activities of polysaccharide extracts from a Se-enriched mushroom species of the genus Ganoderma. European Food Research and Technology, 226, 499-505. https://doi.org/10.1007/s00217-007-0562-7

Zheng, Q., Ren, D., Yang, N., \& Yang, X. (2016). Optimization for ultrasound-assisted extraction of polysaccharides with chemical composition and antioxidant activity from the Artemisia sphaerocephala Krasch seeds. International Journal of Biological Macromolecules, 91, 856-866. https://doi.org/10.1016/j.ijbiomac.2016.06.042

Zheng, C., Dong, Q., Chen, H., Cong, Q., \& Ding, K. (2015). Structural characterization of a polysaccharide from Chrysanthemum morifolium flowers and its antioxidant activity. Carbohydrate Polymers, 130, 113-121. https://doi.org/10.1016/j.carbpol.2015.05.004 
Zhou, C., Wang, Y., Ma, H., \& He, R. (2008). Effect of ultrasonic degradation on in vitro antioxidant activity of polysaccharides from Porphyra yezoensis (Rhodophyta). Food Science and Technology International, 14, 479-486. https://doi.org/10.1177/1082013208100665

Zhu, J., \& Wu, M. (2009). Characterization and free radical scavenging activity of rapeseed meal polysaccharides WPS-1 and APS-2. Journal of Agricultural and Food Chemistry, 57, 812-819. https://doi.org/10.1021/jf802687t

\section{Copyrights}

Copyright for this article is retained by the author(s), with first publication rights granted to the journal.

This is an open-access article distributed under the terms and conditions of the Creative Commons Attribution license (http://creativecommons.org/licenses/by/4.0/). 